\title{
Valuation of Strategic Options in Public-Private Partnerships
}

\author{
Gabriel J. Power ${ }^{1}$ \\ Department of Finance and Insurance \\ Laval University (Canada) \\ Mark Burris ${ }^{2}$ \\ Department of Civil Engineering and Texas Transportation Institute \\ Texas A\&M University \\ Sharada Vadali ${ }^{3}$ \\ Economics, Trade and Logistics Group \\ Texas A\&M Transportation Institute \\ Texas A\&M University \\ Dmitry Vedenov ${ }^{4}$ \\ Department of Agricultural Economics \\ Texas A\&M University
}

${ }^{1}$ Corresponding author: 2325 Rue de la Terrasse, office \#3654 Pavillon Palasis-Prince, Quebec City, QC, Canada, G1V 0A6, Phone : 418-656-2131 \#4619, fax : 418-656-2614, email:

Gabriel.power@fsa.ulaval.ca

${ }^{2}$ CE/TTI Building Room 301B, 3136 TAMU, College Station, TX 77843, Phone: 979-845-9875, fax: 979-845-6481, email: MBurris@tamu.edu

${ }^{3}$ Mobility Analysis - CE/TTI, Room 402F, Texas A\&M Transportation Institute, The Texas A\&M University System, 3135 TAMU, College Station, TX 77843-3135. Phone: (979) 845-3325 \#53325, fax: (979) 845-6008, email: s-vadali@ttimail.tamu.edu

${ }^{4} 364$ AGLS Building, 2124 TAMU, College Station, TX 77843-2124. Phone: (979) 845-8493, fax: (979) 862-3019, email: vedenov@tamu.edu 


\begin{abstract}
This paper investigates the feasibility of and develops an economic valuation model for buyout options in Comprehensive Development Agreements (CDAs). A CDA is a form of public-private partnership whereby the right to price and collect revenues from toll roads is leased to a private entity for a finite but lengthy period of time in exchange for providing local and state governments with a quick influx of cash and/or additional infrastructure. Uncertainty associated with such long-term leases is of substantial public concern. In particular, there is a sentiment that the state and/or municipal governments may not be sufficiently compensated for the forfeited development opportunities and a possibility of lost revenue due to higher-than-expected future growth during the lifetime of the lease. An under-studied aspect of the problem is the feasibility and economic value of an option for the government to buy back the leased infrastructure at a future date prior to lease expiration. Such an option would give the public sector additional control over the future use of leased facilities and address potential concerns regarding long-run uncertainty and possible unforeseen windfalls for the private sector. The buyout option valuation model developed in the paper could help transportation policymakers in decisions on leasing public infrastructure. The paper's contributions include the analysis and feasibility assessment of buyout and revenue-sharing options, an economic consumer demand-based revenue model for purposes of simulation, and the numerical evaluation of the strategic options. The main conclusion is that buyout and revenue-sharing options tend to have a high cost relative to the value of the lease. It is therefore understandable that private sector developers are hesitant to allow such clauses to be included without significant compensation.
\end{abstract}




\section{Introduction}

In 2009, the Federal Highway Administration's Trust Fund faced a shortfall of $\$ 20$ billion, despite the addition of $\$ 8$ billion to the Fund by the U.S. Congress in 2008 (Crawley and Lambert, 2009; Government Accountability Office, 2008). The Trust Fund's financial condition improved in 2010 , ending the fiscal year with a balance of $\$ 29.2$ billion. However, this was a result of "[...] Congress's General Fund cash infusions and a decline in outlays due in part to the roughly \$36 billion that the American Recovery and Reinvestment Act of 2009 (ARRA) provided to States for highway infrastructure and mass transit projects" (U.S. Departement of Transportation, 2012, p.2).

The Fund was established shortly after 1956 legislation that created the Interstate Highway System, and was intended to be funded using federal gasoline taxes. In the last 25 years, however, the Trust Fund has been eroded, mainly by the lack of an increase in federal gas taxes, which remain at 18.4 cents per gallon, together with increases in vehicle efficiency (Puentes and Prince, 2003). In contrast, the cost of building roads and bridges has steadily increased. At the state level, transportation budgets were already in difficulty before the 2008 financial crisis and subsequent Great Recession.

To address this budgetary crisis, proponents of innovative financing have suggested transportation public-private partnerships, such as Comprehensive Development Agreements (CDAs), as one of the delivery mechanisms. A CDA is a form of public-private partnership whereby the right to price and collect revenues from toll roads is leased to a private entity for a long but finite period of time, in exchange for providing local and state governments with an initial influx of cash and/or additional infrastructure. These arrangements include concessions and leases, can be used for new or existing projects, and generally involve design, construction, 
operation, and, eventually, transfer of the facilities. Typically, a higher degree of privatization of the project implies greater risk transference from the public sector to the participating private firm or consortium (see figure 1).

[Figure 1 about here]

This paper develops an analytical framework to value strategic options in CDAs, with an emphasis on new (Greenfield) transportation projects. While much of the literature uses simulation methods directly applied to cash flow projections (e.g., Cheah and Liu, 2006), this paper considers how a wide range of variables interact to generate cash flows. This approach makes it possible to conduct parameter-specific sensitivity analysis of lease prices or option values.

We consider a buyout option and a revenue-sharing option. The first is modeled as Bermudan exercise style, while the second is a sequence of European options. The options considered in this paper are expected to take the form of clauses written into CDA contractual agreements, and would be explicitly priced, as the party would pay a predetermined amount to have the option included in the agreement. If the options are included in the contract at no cost, or not included at all, the solutions obtained are still of interest because they represent the value foregone by one of the parties.

The paper's findings suggest that both option types are expensive relative to the total value of the CDA. Given the large value of the options, it is unlikely that the private sector developer or consortium would allow their inclusion without compensation. Therefore, while the options may play an important role in reducing risk for the public sector, their inclusion may be costly. However, the options' inclusion in CDAs could be made more affordable by scaling 
down the option payoffs. The options would still provide the government with useful risk reduction, but would not limit as much the developer's upside potential for profits.

\section{Problem Statement and Literature Review}

For private firms, public-private partnerships are appealing as an asset class because they are broad-based and essential, they are real assets, they provide returns that are stable in the long run (assuming accurate project forecasts), and there are natural barriers to entry, even without the inclusion of a non-compete clause (discussed in more detail below).

For public authorities, entering into public-private partnerships is expected to provide a number of benefits. The main benefit is that while the public generally faces a lack of funds, the private sector is interested in considering new investments to diversify financial portfolios. Further advantages include the private sector's ability to use economies of scale, diversify its investment as a part of a larger portfolio of real and financial assets, provide financial innovation, generate greater leverage than the public sector, and monetize the projected revenue. In particular, the private sector can potentially leverage state funds towards transportation projects.

The public sector generally uses municipal bond market tax-exempt debt to finance transportation projects, which is in fact a subsidy whose cost to taxpayers should not be ignored. The use of tax-exempt funding creates the illusion of a lower cost of borrowing. Moreover, the high rating of municipal bonds also implies that the public sector has limited borrowing ability, compared with the private sector. Indeed, funding in the private sector usually consists of a mix of senior debt and equity, and the longer time horizon of investors allows for a greater capacity to borrow.

CDAs, and more generally transportation public-private partnerships, have been used in several U.S. states as well as in Canada, Australia, and in many European, Latin American, and 
Asian countries. Although many are considered quite successful, such projects are frequently controversial. ${ }^{5}$ CDAs are classified as Greenfield or Brownfield projects. A Greenfield project consists of new construction, often in a newly developed area. In addition to construction risk, such projects face substantial revenue uncertainty associated with difficult-to-forecast demand for the new project, particularly if the geographical location is still in economic development. Indeed, in some cases the urban development fails to materialize and there is almost no demand for the project. In contrast, a Brownfield project is a mature one, typically already built and located in a well-established city or region. There is much less risk, and less demand uncertainty, associated with the upgrade of a Brownfield project compared with new construction (Greenfield). There exists a clear relationship between project maturity and the risk premium expected by investors. The risk premium is very high for Greenfield projects, but falls sharply as projects become more mature, i.e., for Brownfield projects. For example, research done by the Macquarie Infrastructure Group (undated) on the profitability of the Indiana toll road finds that the risk premium is at least 7 percent for new construction projects such as South Bay or Westlink M7, but only about 3 percent for established projects such as Lusoponte or M4 or M5 Motorways.

The case of SR-91 in California, an urban type of CDA, provides a good overview of the issues. Developers may worry not only about uncertainty in revenue streams but also the likelihood that the public sector will wish to change the terms of the agreement if the latter

\footnotetext{
${ }^{5}$ In Texas, plans for an ambitious Trans-Texas Corridor to be built through CDAs were developed by Governor Perry, but the state legislature strongly endorsed in June 2007 a two-year moratorium on CDAs. In July 2009, the legislature voted against the potential use of CDAs in transportation, and instead authorized $\$ 2$ billion in bonds for road building and other contracts. However, CDAs that had already been approved were not bought back. For example, SH-130 in Texas is expected to continue as planned. While the first segments were opened in 2006, two additional segments are being built by Cintra-Zachry as part of a $\$ 1.3$ billion agreement whereby the developer can collect tolls for a period of 50 years, with a revenue-sharing provision with the State of Texas.
} 
appears to be too profitable for the developer. Moreover, the literature finds clear evidence of optimism bias. For example, Bain and Wilkins (2002) find that only four out of 32 toll road cases studied reached their forecasted performance. On average, actual volume was only 70 percent of the volume forecast.

In some cases, there has been conflict over improvements to be made to nearby (competing) freeways. In 1995, the State of California awarded a private firm with a BuildOperate-Transfer (BOT) contract to improve the congested Route 91 (SR-91) by adding to the highway a 10-mile high occupancy/toll (HOT) lane. The HOT lane would relieve congestion by allowing motorists to pay a toll to access it, while drivers in high occupancy vehicles would enter at no cost. The firm paid $\$ 128$ million for a 35-year lease, after which time it would return to the Government the tollway in good condition along with all rights to collect tolls.

Eight years later, the Government paid the developer $\$ 207.5$ million to buy back operating rights to SR-91. The reason why the buyback price was higher than the initial concession price is that, first, the HOT lane addition to SR-91 was a success. Indeed, the number of vehicle trips increased from 5.69 million in 1996 to 9.27 million in 1998, and despite several toll rate increases stabilized around 8.25 million. Second, the State of California wanted to further relieve congestion through improvements to adjacent freeways, but was unable to do so because the SR-91 lease included a strict no-compete clause prohibiting road improvements that would reduce the developer's revenue stream.

Concession prices and durations have also attracted much attention. Two examples are the 99-year lease of the Chicago Skyway for $\$ 1.83$ billion and the 75 -year lease of the Indiana Toll Road for $\$ 3.8$ billion. In both cases, the winning bid was much larger than the secondhighest one, suggesting perhaps a so-called winner's curse. Curiously, the prices paid were about 
five times the price of similar French concessions. Therefore, the concession price as a multiple of earnings was about 60 for the U.S. concessions but only about 12 for the French concessions. According to Bel and Foote (2007), this is because contract provisions (general restrictions, toll rate increase limitations, buyback provisions, etc.) are in some regards remarkably different. While U.S. concessions were designed to maximize taxpayer welfare, European concessions maximized toll-payer welfare.

Meanwhile, public agencies considering CDAs are concerned about possibly conflicting incentives of developers, e.g., efficient toll collection vs. smooth traffic flow, and also about relinquishing too many rights to developers, particularly regarding toll increases or improvements to competing roads. Local and state governments have been under fire from the media and various citizen associations, as CDAs are interpreted as handouts given to private companies and consortiums involved in CDAs. This can appear surprising in light of the evidence that CDAs, particularly Greenfield (see below) projects, greatly suffer from optimism bias and are more likely than not to be investment losses (Bain and Wilkins, 2002; Bain and Plantagie, 2007).

This paper considers one approach to facilitate CDAs by making the provisions more appealing and flexible to the public sector, through the introduction of strategic options that may reduce revenue uncertainty and reduce the likelihood that CDAs will be interpreted as a windfall for private sector developers at taxpayers' and road users' expense.

\section{Methodology}

\subsection{Can Options Facilitate Comprehensive Development Agreements?}

For both the public and private parties, the main concern is uncertainty associated with difficult-to-forecast revenue streams over a very long period of time. CDAs are often several 
decades long and can be as long as 99 years, in the case of the Chicago Skyway. Options provide a means to reduce uncertainty for both parties. The literature has focused so far on options for private developers, such as minimum revenue guarantees (Cheah and Liu, 2006; Chiara, 2006; Chiara and Garvin, 2008; Chiara, Garvin, and Vecer, 2007). However, the benefits of innovative financing continue to be a source of debate.

Sources of risk are numerous and varied. Broadly, they may be categorized as risk due to: (i) revenue generation, (ii) operation and maintenance, (iii) government actions and force majeure, (iv) termination or counterparty payment uncertainty, and (v) disputes. Since this paper examines formal buyout option clauses in CDAs, risk categories (iv) and (v) are assumed to be negligible. However, such is not always the case.

Post-implementation, the main source of uncertainty is business risk associated with uncertain demand for the toll road, depending on regional and national macroeconomic conditions, and also if a non-compete clause has not been included, such that improvements to nearby freeways can create substantial diversion from the tollway. Clear delineations of risksharing between public and private parties is often difficult and contracts may lack in transparency (Peters and Perotta, 2006). An especially worrisome source of risk for the private sector and one that is difficult to evaluate is political risk, for example, uncertainty associated with new political leaders or parties who did not support the previous administration's endorsement of a CDA or a change in legislative provisions.

This section defines problem motivation, suggests the use of strategic options both for public and private parties to provide insurance and increase the mutual appeal of CDAs, and finally describes analytically the four options modeled in this paper, three from the public agency's perspective and one from the developer (concessionaire). 


\subsubsection{Buyout option}

The Texas legislature strongly favored a clause generally known as "termination for convenience," which involves the public agency buying back the CDA at its own discretion. In the past, the buyout price was negotiated ex-post. For example, the SR-91 toll highway in California was first leased for \$128 million and was bought back eight years later for \$208 million. Why the lease increased in value when there were eight fewer years worth of cash flows to collect remains an interesting question and further motivates the concept of a buyout option.

Consider a Greenfield CDA with a duration of 50 years that is initially valued at $\$ 400$ million, based on limited information forecasts. Once the tollway opens, it becomes clear that demand is higher than expected, and moreover regional growth is greater than expected. After five years, the revised value of remaining cash flows is $\$ 800$ million. In the public's eye it may appear that developers received too sweet a deal, putting pressure on political leaders who seek reelection. We therefore consider a contractual clause giving the public authorities the right to buy back the CDA for a predetermined exercise price. Rose (1998) studies a special case of a buyout option with an application to Australian transportation public-private partnerships.

This contract clause was strongly favored by a Texas legislature concerned about developers collecting excessive profits on Greenfield CDAs. Here the public agency has an option to buy out the lease and recover the remaining cash flows, either to collect itself or to lease out to a new private firm. This is modeled as an American call option. The public sector wants to retain the privilege of buying back the concession at any future date for a predetermined price. Assume this exercise price equals the price of the concession paid by the developer to the public sector, although it can be defined otherwise. How much would this option cost? 
The equivalent of asset price in this case is the revised net present value (NPV) of remaining cash flows. Every period, more information is learned about the profitability of the concession. It is likely that the greatest amount of uncertainty is resolved in the first few periods. The revised NPV must decrease, other things being equal, because there are fewer years worth of cash flows remaining, but if traffic volume is substantially greater than expected ex-ante, it may more than offset the loss of cash flows and thus lead to a revised NPV that is greater than the exercise price. A necessary condition for the buyout option to be exercised is that at any period the revised, period-t NPV be greater than the exercise price. A sufficient condition is that the period of exercise be the optimal stopping time. The problem is therefore one of solving for the optimal stopping time.

For option pricing purposes, we solve the closely related problem of a multiple-exercise time Bermudan option. Such an option can be exercised at any of $T$ different dates. The dates could be the end of each fiscal year, or once each month. In the present study the dates are the smallest time frequency used, e.g., monthly. Since this option is priced from the perspective of the public sector, the revised NPVs are calculated using a lower discount rate than that used for the developer. Finally, to price the option by Monte Carlo, we evaluate the expectation of the option payoff over all paths, discounted using the risk-free rate (actually, risk-free rate simulated paths). This point is further discussed in the paper's section on computational methods.

\subsubsection{Revenue-sharing option}

This type of clause is favored by private sector firms involved or considering involvement in CDAs. It provides the public agency with a share of revenues in the event that the latter would be much higher than what was anticipated at the time the contract was signed. The option is defined such that if net revenues exceed a predetermined amount, then a share $\alpha$ of 
excess profits is returned by the developer to the Government, while the developer retains a share $(1-\alpha)$.

This clause is modeled as $T$ distinct European call options each with price $\mathrm{CE}_{\mathrm{i}}$ for $t=$ $\{1, \ldots, \mathrm{T}\}$. At the end of each period $t$ (e.g., financial year), the period's net revenues $S_{t}$ are compared with the predetermined value of so-called "normal" profits (exercise price) denoted $K$. If $\left(S_{t}-K\right)>0$, that is the updated current-period NPV of remaining revenue flows is greater than the strike price (original value of CDA), then the public agency should exercise its option and will obtain a payoff equal to the revenue-sharing fraction $\alpha$ times the difference between the actual revenues in period $t$ and the expected period-t revenues, if and only if it is positive; otherwise zero. The total cost to the public agency of purchasing all $T$ options is the sum of the $T$ option prices. Note that because the $T$ options are based on different samples from the same unknown stochastic process, solving for their prices independently may introduce a small bias.

\subsection{Revenue Model}

This section describes the consumer demand-based model developed for simulation purposes. Most of the literature takes the approach of directly simulating cash flows, from which option prices can be solved using Monte Carlo methods. Instead, this paper develops a framework in which all financially relevant variables are modeled and simulated individually. Cash flows result from the interaction of these simulated variables. For purposes of simulation, we use a monthly frequency, such that a lease with a duration $T=50$ years would consist of 600 periods.

The baseline model considered is a BOT Greenfield CDA with a contract period of 50 years. The developer is responsible for the project construction, and subsequently begins operation and toll collection for a period of 50 years. The CDA itself is a six-lane toll highway. 
Model calibration is based on a careful review of the literature on transportation CDAs (e.g., Bain and Wilkins, 2002; Chiara, 2006; National Cooperative Highway Research Program, 2006). Parameters are determined following the literature's findings. Ideally, parameters should be estimated using econometric methods and historical data. Data on Greenfield projects in North America are, however, limited because these projects are few. Projects on other continents are more numerous, but the economic conditions and political climate may be vastly different.

To evaluate the robustness of the option price solutions to the parameter specification, a later section of the paper presents a thorough sensitivity analysis conducted by varying parameter values along a range, keeping all other parameter values constant. For convenience, all model parameters are summarized and briefly described in table 1.

[Table 1 about here]

\subsubsection{Maturity of the project}

The main difference between Greenfield and Brownfield projects is project maturity, as well as maturity of the project location. This translates into different levels of uncertainty in demand and demand growth. In a Brownfield project, there is a history of demand data available, so forecasts are generally reliable. Moreover, the project is mature and the city or region is already developed, so traffic growth will generally be small but consistent. On the other hand, with a Greenfield project forecasts of initial traffic and subsequent growth are unreliable because the project is not yet built, there is no demand to observe, and it is difficult to use data from established Greenfield projects elsewhere in the country because conditions can be vastly different. This paper focuses on the case of a Greenfield project because uncertainty is much higher, but the framework allows for analysis of options in a Brownfield project, if the model parameters are appropriately adjusted. 


\subsubsection{Construction risk}

Risk in construction costs and duration are substantial in Greenfield projects. Despite performance measures, cost overruns are not uncommon (Bain and Plantagie, 2007), and new projects can be delayed by political or environmental concerns, as in the case of the I-80 in Pennsylvania and New Jersey. The New Jersey Turnpike and Garden State Parkway privatization plan is referred to as monetization in New Jersey.

To account for the role of political and environmental risk leading to higher costs and/or delayed construction, we assume that both cost and duration of construction are stochastic. Clearly, the actual cost of construction affects the developer's profits, while the duration of construction delays the opening of the project, thereby reducing the NPV of the cash flows from the lease.

Assume a year's worth of construction cost follows a truncated lognormal distribution with mean of $\$ 200$ million. Construction duration also follows a truncated lognormal distribution with mean equal to three years. The total cost of construction is therefore a random variable itself and equals the product of $M$ years times the respective stochastic annual costs $C_{m}$. On average, the project would cost $\$ 600$ million, and this is the value included in the concession price (adjusting to current value dollars). Following the literature, we assume that total cost is roughly monotonic in the duration of construction, such that the random variables for duration and for annual cost are independent. Specifically, $\ln M$ is distributed as truncated $\operatorname{Normal}\left(\mu_{M}, \sigma_{M}^{2}\right)$ and $\ln C$ is distributed as truncated $\operatorname{Normal}\left(\mu_{C}, \sigma_{C}^{2}\right)$ such that the total project cost equals the sum of $M$ different annual costs. 
For purposes of model tractability, we ignore the costs associated with a project being terminated before construction begins (e.g., costs of planning and development) and we also assume that once construction begins, it can only be delayed, not cancelled.

\subsubsection{Cost of capital and discount rates}

For purposes of discounting, we use the Capital Asset Pricing Model and assume no leverage, so this can be interpreted in terms of the weighted average cost of capital (WACC). The developer uses the rate $r_{e}=r_{f}+\beta\left(r_{m}-r_{f}\right)$ where $r_{f}$ is the risk-free rate (e.g., the threemonth Treasury bill yield), $\beta$ is the company or sector financial beta, and $r_{m}$ is the market portfolio return. The difference between $r_{e}$ and $r_{f}$ is the individual risk premium, while the difference between $r_{m}$ (in expectation) and $r_{f}$ is the market premium. The empirical literature for transportation finance finds that $r_{e}$ generally is in the range of 8 to 10 percent, typically below the Internal Rate of Return (IRR) for successful projects. For example, the IRR for SR-91 in California was about 17 percent, while the fair market value rate of return for SH-130 in Texas was 18 percent. The public sector is expected to use a lower discount rate, for instance one related to long-term bond rates such as municipal bonds. The choice of the public sector discount rate should be motivated by its financing alternatives to CDAs, e.g., municipal bond rates.

\subsubsection{Traffic model parameters}

The following presents a description of the model parameters, the values used based on the research literature, and their interpretation. The model primitives are parameters for the peakhour proportion of traffic, proportion of trucks and axle equivalent (for toll rate and road damage purposes), proportion of toll violations, and peak-hour traffic volume in vehicles per hour per lane (vphpl). 
The peak-hour proportion of traffic volume is a fraction between 0 and 1 that describes how much of a day's traffic volume occurs during peak hour(s). This value is typically 0.07 to 0.11. The proportion of trucks as a fraction of total vehicles is important to accurately estimate toll revenues as well as road damage. Instead of assuming a flat toll rate for all trucks, we model different axle-classified truck categories, since truck toll rates are usually axle-based as well. This allows us to define a single toll rate $P$ which becomes the developer's principal decision variable. Trucks are then charged an axle-based multiplier of $P$, in effect paying a toll equal to that of several cars.

For toll road segments near state or national borders, enforcement of toll payments can be more difficult, and a fraction of users will escape toll payment enforcement. A proportion of toll avoidance is specified based on geographical location of the toll road segment. Lastly, peak-hour traffic volume in terms of vphpl is specified, where, for example, 1800 would correspond to relatively dense free-flow traffic, while 1200 would be light, and 600 would be very sparse.

To compute the annual traffic volume corner solution $\mathrm{A}_{0}$ (corresponding to a toll rate or rate vector $P=0$ ), we first obtain the effective peak-hour volume adjusted for truck axle-based equivalent volume and toll rate violations, then divide by the peak-hour proportion to obtain daily volume per lane. Next we multiply daily volume per lane by the number of lanes in the toll road and the number of effective days in a year. Effective days represent a way to annualize daily traffic when it is clear that traffic varies according to the day of the week, for example work commuting as opposed to weekend trips. The parameter $A_{0}$ represents a baseline scenario measure of annual traffic volume and is used in the demand model to derive actual quantity or volume of traffic. 


\subsubsection{Demand model}

Assume that quantity demanded, i.e., traffic volume, equals $Q=A(P+\psi)^{-\gamma}$ where $A$ is determined as explained above, $P$ is the unit toll rate or vector of rates, $\gamma$ is a parameter defining price elasticity of demand, and $\psi$ is a parameter ensuring that traffic volume reaches a finite value as price goes to zero. The no-toll corner solution is then $Q=A \psi^{-\gamma}$. An upper bound reflecting maximum capacity is imposed to ensure that traffic volume does not grow unboundedly. This maximum capacity is defined as the traffic volume beyond which safety becomes an issue.

The developer's problem is to choose an optimal toll rate $P^{*}$ such that revenue is maximized, subject to the following constraints:

- $\quad P$ and $Q$ are non-negative.

- Maximum allowed toll rate increase constraint: the annual percent increase in $P$ is limited, through contractual agreement, to be no greater than the maximum of three values, namely a predetermined constant, the annual inflation rate, and the real Gross Domestic Product (GDP) growth rate. The constant is contractually set. Interestingly, we found that the constraint is nearly always binding, a plausible outcome given the low elasticity of demand. Therefore, the developer typically uses the full allowed toll rate increase.

- Level of service constraint: traffic volume must not exceed the volume $Q_{0}$ at which average speed reaches the minimum speed $V_{0}$ as defined in the CDA to ensure steady movement of traffic. For example, $V_{0}=80 \mathrm{~km} / \mathrm{h}$. If average speed falls below $V_{0}$, the developer is penalized a large share of the period's revenues, e.g., at least 25 percent and as much as 100 percent. To avoid adding one more variable, we transform this minimum 
speed constraint into a maximum quantity constraint using a congestion correspondence based on Li's (2008) modification of the Newell-Franklin speed-flow model:

$$
Q=Q_{0}\left(\frac{V}{V_{0}}\right)\left(1-\frac{1}{B} \ln \left(\frac{V_{f}-V}{V_{f}-V_{0}}\right)\right)^{-1}
$$

where $Q$ and $V$ are the actual traffic quantity (volume) and average speed, respectively, $V_{f}$ is the free-flow traffic speed, e.g., $V_{f}=110 \mathrm{~km} / \mathrm{h}, V_{0}$ is the contractually determined minimum average speed below which the developer is financially penalized, $Q_{0}$ is the traffic volume above which speed falls below $V_{0}$, and lastly $B=V_{0} /\left(V_{f}-V_{0}\right)$. This correspondence allows us to turn the minimum average speed constraint into a maximum traffic volume constraint in the developer's revenue maximizing problem. Additional results (available upon request) suggest that, for the model parameters considered, incurring penalties by letting $Q>Q_{0}$ is never optimal. Note that in Greenfield projects, however, the constraint is generally non-binding, because even with healthy traffic growth, volume remains far below $Q_{0}$. Nonetheless, we include the constraint in the model, for example in the event of an exceptional growth boom.

\subsubsection{Traffic volume, growth rates and ramp-up period}

Assume the rate of traffic growth contains both stochastic and deterministic components. The shape of the traffic growth curve is calibrated using estimates and data from actual projects. Previous evidence suggests that, generally speaking, traffic volume in Greenfield projects should be first convex increasing in time, then reaches an inflection point, and finally becomes concave increasing in time. Although traffic volume must be asymptotically bounded above, this bound is not expected to be reached in a Greenfield project. For example, U.S. interstate highways can be considered early Greenfields and these never reached upper bounds. Thus, given time we should 
not expect new Greenfields to reach them either. For purposes of valuing the lease, the expectations (means) of stochastic components are used.

For a Greenfield project, traffic growth rates for all periods $t$ are modeled as:

$$
g_{t}=g_{0} \exp \left(-\omega t+\sum_{\tau=1}^{t} v_{\tau}\right)
$$

where the first-period growth rate $g_{0}$ is distributed as Uniform over the support 0.15 to 0.50 , and so has an expectation of 0.325 . In subsequent periods, the growth rate $g_{t}$ is expected to decrease gradually at the exponential rate $\exp (-\omega t)$, not including random shocks, $v_{t}$ representing local or regional economic/demographic growth. In the baseline model, $\omega=0.20$, and $v$ is distributed as truncated $N\left(0, \sigma_{v}^{2}\right)$ over the support $[-3 \sigma, 3 \sigma]$. These values were selected to eliminate the possibility of unrealistic outliers. The parameter values are calibrated to replicate growth and volume trend data from existing Greenfield project data. Traffic growth should be correlated with regional population or economic growth, but since the latter variable is not used elsewhere, it is excluded from the set of simulated variables and it is assumed that traffic growth implicitly reflects localized population growth.

Traffic volume in each period is determined as follows. First, the developer increases toll rates according to the formula defined earlier allowing for the maximum of a constant, inflation, or real GDP growth. In theory, the developer does not need to increase toll rates as much as allowed, but in the present simulations it seems it is always optimal to do so. The increase depends on the realized values taken by the simulated paths of real GDP and inflation. These simulations are generated from time series models whose parameters are estimated using historical data. In each case, an autoregressive (AR) and moving average (MA) time series model is fitted to the data. Note that if a historical time series is found to be nonstationary, i.e., contains a unit root, the model is estimated in differences. To determine the optimal number of AR and 
MA parameters, first a large-scale model is estimated, and then likelihood ratio tests are used to remove parameters one at a time until the most parsimonious specification is obtained. Although there is a large economic literature base on the use of the Phillips curve to forecast inflation, Atkeson and Ohanian (2001) show that such models cannot beat naive models. The economic literature does not suggest a single, clear model to forecast real GDP.

Second, traffic growth $g_{t}$ is computed using the above equation together with a draw of the random variable $v$. Traffic growth $g_{t}$ affects the parameter $A$ in the demand model, as the traffic growth moves to the right the entire demand curve, as well as the intercept at $P=0$. Effectively:

$$
\begin{aligned}
A_{t} & =A_{0} \exp \left(g_{t}\right) \\
& =A_{0} \exp \left\{g_{0} \exp \left(-\omega t+\sum_{\tau=1}^{t} \nu_{\tau}\right)\right\}
\end{aligned}
$$

The demand equation for $Q$ is revised using the new value of $A$. Third, a new traffic volume $Q_{t}$ is computed from the demand equation using the new, period-t values $P_{t}, A_{t}$, and $\gamma_{\mathrm{t}}$. The latter parameter is further discussed in the sub-section on non-compete clauses.

\subsubsection{Operation and maintenance costs}

Operation and maintenance costs are modeled as a simple affine function of traffic volume, as the engineering literature suggests that variable costs are relatively small.

\subsubsection{Non-compete clause}

A key provision in a CDA is whether a non-compete clause is included. Such a clause can have important and expensive consequences, as shown by SR-91 in California. In the baseline model, we exclude the non-compete clause because public authorities have been, particularly since SR-91, reticent to allow them. However, the effect of allowing a non-compete clause is examined in the section on sensitivity analysis. 
The elasticity parameter $\gamma$ is assumed to be relatively high at the beginning of the Greenfield project, implying elasticity. Over time, however, it decreases according to a deterministic time trend, as drivers become accustomed to using the toll road. In the absence of a non-compete clause, there is a chance every period that improvements will be made to alternative, i.e., competing roads. These road improvements affect the demand for the toll highway by increasing the elasticity parameter $\gamma$, because drivers have more choices and as a result are more flexible. The effect of competing road improvements is captured through a Bernoulli process. Each period, a single Bernoulli(p) draw is made. A Bernoulli success is interpreted as improvements made to competing roads such that $\gamma$ increases by an amount distributed as truncated Normal.

An important issue that is, however, beyond the scope of this paper is to evaluate externalities associated with diversion of traffic to alternative roads following toll increases. If diversion is substantial, congestion on toll-free, alternative roads may increase the cost associated with time lost in congestion as well as the number of accidents.

\subsubsection{Corporate taxes}

The developer's profits are generally taxable, although CDAs sometimes include certain tax exemptions. Based on the literature for U.S. CDAs, it is assumed that the developer pays a corporate tax rate of 28.5 percent on all revenues net of debt service payments, operating and maintenance costs.

\subsubsection{Debt service}

Since the developer borrows funds to pay for the concession, it must pay debt service on this loan. Debt service payments reduce net profits. We assume that a fraction $\varsigma$ of the expected total cost of the CDA (construction plus lease) consists of equity, while the remainder $(1-\zeta)$ 
consists of senior debt. Once the agreement is signed, the amount of equity is fixed. If there is construction cost overrun, the excess costs are paid for using additional senior debt. The total amount of senior debt is then paid back in equal, annual debt payments over the entire duration of the lease. For example, suppose the project's cost is $\$ 1.8$ billion, including $\$ 600$ million for construction and $\$ 1.2$ billion for a 50 -year BOT agreement. Sponsors provide equity in the amount of $\$ 450$ million, to be repaid at an expected rate of 15 percent, while the remainder, $\$ 1.35$ billion is loaned as senior debt with an interest rate of 10 percent. Structuring the debt repayment is a key part of establishing profitability of the concession.

\subsubsection{Interest rates}

To price an option with a short time-to-expiry, using a constant risk-free rate may be acceptable. The options associated with CDAs, however, can have maturities of up to 50 years, during which time interest rates will surely vary substantially. Note that although the Indiana and Chicago Skyway agreements are for 75 and 99 years, respectively, legislation limits CDAs in Texas to have durations of no more than 50 years. Instead of a single, fixed risk-free rate $r, N$ different time series paths $\left\{r_{t}^{n}\right\}$ are generated corresponding to $N$ Monte Carlo simulation runs.

To simulate interest rate paths, we use information provided by the yield curve implied from Treasury bill and bond prices which correspond to market expectations of future interest rates. Moreover, historical data on interest rates can be used to estimate mean-reverting interest rate models. The best-known models are those of Vasicek (1977) and Cox, Ingersoll and Ross (CIR). The Vasicek model is essentially an Ornstein-Uhlenbeck (mean-reverting) stochastic process. Though convenient, it has a notable weakness in that it admits a positive probability of negative interest rates. The more widely used CIR model, based on Feller's classic work, models interest rate volatility as proportional to the interest rate level and ensures non-negative interest 
rates. More recently, Chan, Karolyi, Longstaff, and Sanders (CKLS, 1992) developed a general framework that nests several models including the Vasicek and the CIR specifications. The CKLS model is estimated using historical interest rate data, with the CIR and Vasicek models considered as special cases. The value of this approach is that it enhances the model's robustness to uncertainty in future interest rates.

To simulate the risk-free interest rate paths, we first estimate, using the General Method of Moments (GMM), the parameters of a model capturing interest rate dynamics. The models are first written as continuous time, stochastic differential equations. The CKLS model is:

$$
d r_{t}=a\left(b-r_{t}\right) d t+\sigma r_{t}^{\lambda} d W_{t}
$$

For purposes of estimation this is re-parameterized as:

$$
d r_{t}=\left(\alpha+\beta r_{t}\right) d t+\sigma r_{t}^{\lambda} d W_{t}
$$

where the CIR and Vasicek models emerge as special case with $\lambda=0.5$ and $\lambda=0$, respectively. To estimate the model in a GMM framework, we follow the approach of CKLS. First, we obtain an Euler discretization of the continuous-time model:

$$
\begin{aligned}
\Delta r_{t} & =\alpha+\beta r_{t-1}+\varepsilon_{t} \\
\varepsilon_{t} & =\sigma r_{t}^{\lambda} u_{t}
\end{aligned}
$$

where $u_{t}$ is an IID shock distributed Normal $(0,1)$. To derive moment conditions, consider the following facts: $\mathrm{E}\left[\varepsilon_{\mathrm{t}}\right]=0, \mathrm{E}\left[\varepsilon_{\mathrm{t}}^{2}\right]=\sigma^{2} r_{t}^{2 \lambda}$ and $\mathrm{E}\left[\varepsilon_{\mathrm{t}} \mathrm{r}_{\mathrm{t}-1}\right]=0$. This allows us to obtain the following four moment conditions:

$$
\begin{aligned}
\mathrm{E}\left[\varepsilon_{t}\right] & =0 \\
\mathrm{E}\left[\varepsilon_{t} r_{t-1}\right] & =0 \\
\mathrm{E}\left[\varepsilon_{t}^{2}-\sigma^{2} r_{t-1}^{2 \lambda}\right] & =0 \\
\mathrm{E}\left[\left(\varepsilon_{t}^{2}-\sigma^{2} r_{t-1}^{2 \lambda}\right) r_{t-1}\right] & =0
\end{aligned}
$$

Parameter estimates $\hat{\theta}=\{\hat{\alpha}, \hat{\beta}, \hat{\lambda}, \hat{\sigma}\}$ are solved as the minimization of the following: 


$$
\hat{\theta}=\arg \min J_{T}=g_{T}^{\prime}(\theta) \Omega_{T} g_{T}(\theta)
$$

where $g_{T}$ are the empirical (sample) moments and $\Omega_{\mathrm{T}}$ is a positive definite weighting matrix. The CKLS model is unrestricted and exactly identified, because the model contains four parameters and four moments are used. The CIR and Vasicek models contain three parameters and are therefore under-identified. The two latter models are therefore nested cases whose validity may be tested by imposing the restrictions $\lambda=0.5$ and $\lambda=0$, respectively.

We confirm the literature's finding that the more general CKLS specification is selected while CIR and Vasicek are rejected. The estimate of $\hat{\lambda}=1.5$ approximately leads to a likelihood ratio test rejection of the hypotheses $\lambda=0.5$ and $\lambda=0$. Yet, the CIR model produces the most plausible interest rate paths. Given this finding and also because it is the most widely used model, we use the CIR model to generate interest rate time paths. The simulated interest rate paths are used for purposes of computing risk-free and risky interest rates.

\subsubsection{Valuation of cash flows}

Each period the developer collects cash flows equal to the product of toll rate $P$ and traffic volume $Q(P)$, with $P_{t}$ and $Q_{t}$ computed as described earlier. To price the concession, cash flows are evaluated based on expectations of the model's random variables, and the NPV of cash flows is computed using the risky interest rate $r_{e}>r_{f}$ as defined earlier. If the public sector uses the same discount rate as the developer, the transaction may still be beneficial due to risk transference, the developer's ability to raise toll rates, etc. However, a large literature segment argues that the public sector should use a lower discount rate (Grout, 2003).

\subsection{Option Pricing Solutions: Computational Methods}

The strategic options considered in this paper are American, Bermudan, Asian, and European style. Solutions for all of these options can be computed using numerical methods 
when analytical expressions are unavailable (e.g., American and Bermudan). According to the principles of risk-neutral valuation, the price of an option can be obtained by evaluating:

$$
Y_{t}=\exp (-r(T-t)) \mathrm{E}_{\mathrm{t}}^{\mathrm{Q}} \Pi_{T}^{Y}
$$

where $Y$ is the option price or premium, $r$ is the stochastic or deterministic risk-free interest rate, $(T-t)$ is the option's time-to-expiry, $\Pi_{\mathrm{T}}$ is the option payoff at time $T$, and $\mathrm{E}^{\mathrm{Q}}$ is the expectation taken with respect to the risk-neutral probability measure $Q$.

An appealing approach, since the distributions used for the simulation of random variables in the model are parametric (sometimes truncated), is to use Gaussian quadrature (e.g., Judd, 1998). However, the dimensionality of the problem suggests that simulation methods, i.e., Monte Carlo, may be more appropriate. A different approach that is particularly useful for American options and which is due to Longstaff and Schwartz (2001) consists of least-squares Monte Carlo (LSMC). In this paper, LSMC was used to validate the solutions obtained using Monte Carlo.

With advances in computing power, Monte Carlo methods based on principles of riskneutral valuation have become widely used (e.g., Boyle, 1977; Boyle, Broadie, and Glasserman, 1997; Glasserman, 2003). The major impediment to using Monte Carlo methods is the relatively large confidence intervals around the solutions. This is a direct consequence of the relatively high computational cost of Monte Carlo methods. In particular, parameter standard errors decrease only at the rate $O(\sqrt{ } N)$. To this end, we use 550,000 simulated runs for all variables. All option prices are computed using the same set of runs. The first 50,000 runs are discarded as a burn-in stage, leaving an effective $N=500,000$. For sensitivity analysis, $N=50,000$ runs are used. As the simple Monte Carlo approach leads to relatively large confidence intervals, several variance reduction techniques have been considered since Boyle (1977). The simplest approach 
is the use of antithetic variables, described below. In addition, low discrepancy number sequences (e.g., Halton, Sobol) have been increasingly used, even though they generally do not allow an estimate of the solution standard error. The latter deterministic number sequences are sometimes called quasi-Monte Carlo methods even though they are not at all random.

Antithetic variables are used to reduce the size of Monte Carlo standard errors. The idea is that if we first generate random draws $\left\{U_{i}\right\}_{i=1}^{N}$ then we may also use as additional random draws the sequence $\left\{1-U_{i}\right\}_{i=1}^{N}$. Conditional on certain assumptions, the set of random draws using antithetic variables should have lower variance than a standard set of pseudo-randomly generated numbers. Note that the prices obtained in the paper are the so-called "complete foresight" solutions and should be interpreted as upper bounds to the true solution (Broadie and Glasserman, 1997; Glasserman, 2003).

\section{Findings}

\subsection{Results of the Simulation Model}

This section presents the results obtained for option prices and confidence intervals, as well as an interpretation of the findings. Note that the price of the CDA itself, given the model parameters, is $\$ 456.32$ million. The results are summarized in table 2. The strategic options that most interest public agencies and developers are found to be expensive relative to the value of the CDA or concession.

[Table 2 about here]

\subsubsection{Buyout option}

The buyout option for the baseline CDA has a price of \$122.26 million, with a Monte Carlo standard error of $\$ 0.6153$ million. The option price represents 26.79 percent of the value of the CDA, which is $\$ 456.32$ million. The distribution of optimal stopping times, for paths where 
exercise was optimal, is roughly lognormal with most of the probability mass between 5 and 15 , implying that it is generally optimal to buy back the lease after a few years, but well before the midpoint of the contract duration. These results are particularly interesting because they seem consistent with the case of the SR-91 road in California, which was bought back after only eight years.

\subsubsection{Revenue-sharing option}

The price of the $T$ annual revenue-sharing options (with a share $\alpha=0.5$ going to the public agency) increases nearly monotonically in project maturity, even with discounting. This is because the first few years of operation of a Greenfield project generate little in profits. The fifth-year revenue-sharing option, for example, is priced at only $\$ 27,472$, suggesting it is unlikely the lease will be profitable by that time, while the 25 th year revenue-sharing option is priced at $\$ 1.758$ million and the 50th year option (i.e., the last year) is priced at $\$ 10.629$ million. To acquire revenue-sharing options for all $T=50$ years, the public agency should pay the developer \$150.63 million, which represents 33.01 percent of the value of the CDA. Of course, the options would be more expensive for $\alpha>0.5$ and less expensive for $\alpha<0.5$.

\subsection{Model Uncertainty and Sensitivity Analysis}

The option price solutions described in the previous section are for specific project parameters and are therefore subject to model uncertainty. To evaluate model robustness, we conduct a sensitivity analysis of the solutions by varying key model parameters by \pm 50 percent of the original value. We also include a robustness check for the inclusion of a non-compete clause. The results of the sensitivity analysis are summarized in table 3 . The same random variable draws are used throughout the sensitivity analysis by saving the random number generation seed. We examine the effect of changing model parameter values on the pricing solutions for the 
buyout option only. Note that the option price solution for the basic model was $\$ 122.26$ million given a CDA worth $\$ 456.32$ million. Sensitivity analysis results for the other options are included in an appendix available upon request from the authors.

\subsubsection{Inclusion of a no-compete clause}

Inclusion of a no-compete clause is a controversial proposition. Consider for instance the California SR-91 concession buyback. The developer will ask for a no-compete clause because it restricts the development of alternative roads and thus reduces the elasticity of the demand. To model the no-compete clause, we assume that no random shocks to the demand elasticity parameter $\gamma$ may occur. As a result, the buyout option price increases 42.2 percent to $\$ 173.90$ million. Implicitly, there is substantial value attached to the possibility of making marginal improvements to adjacent roads. The higher value reflects the role in the demand model of allowing for marginal improvements to adjacent freeways. If the public agency is not allowed to make such road improvements, demand is more inelastic than it would be otherwise and revenues increase substantially over time as toll rates increase.

\subsubsection{Interest rate uncertainty}

The buyout option price is computed using risk-free rates simulated from CIR (more generally, CKLS) models, so uncertainty about the CIR model should have an effect on the robustness of the option solution. The solution is found to be robust to uncertainty in interest rate volatility $\sigma$. if the latter is doubled to 0.20 , the buyout option price increases to $\$ 125.92$ million, while halving $\sigma$ to 0.05 decreases the option price to $\$ 121.55$ million. However, the option price is less robust to uncertainty about the long-run interest rate level. If $b$ is doubled to 0.10 , the option price falls to $\$ 98.268$ million, while if $b$ is halved to 0.025 , the price increases to $\$ 137.39$ 
million. Naturally, the value of the lease itself also falls (rises) when the long-run level interest rate increases (decreases).

\subsubsection{Demand model uncertainty}

It is expected that the buyout option price will be sensitive to uncertainty in the demand model parameters. If the standard deviation $\sigma_{\mathrm{Q}}$ of the natural $\log$ of initial traffic volume is doubled from 0.5 to 1 , the option price increases to $\$ 128.97$ million. If, however, $\sigma_{\mathrm{Q}}$ is halved to 0.025 , the option price falls to $\$ 120.09$ million. The changes are of the correct sign but are smaller than expected, given how important the resolution of early period uncertainty is for traffic volume.

[Table 3 about here]

On the other hand, the buyout option price is highly sensitive to the proportion of traffic occurring at peak hour, as this parameter determines total traffic volume. Doubling peak-hour traffic proportion increases the buyout price to $\$ 155.61$ million, while halving it decreases the price to $\$ 66.41$ million. This outcome suggests it is essential to obtain a good forecast of peak and off-peak traffic volume. Likewise, the solution is sensitive to the assumed quantity of peakhour traffic. The baseline value of 1200 vehicles per hour per lane during peak hour is relatively low. If we change the value to 1800 or to 600 , the buyout option price increases to $\$ 140.69$ million or decreases to $\$ 84.74$ million, respectively.

Traffic growth is based on a deterministic component $\omega$, capturing how quickly traffic volume evolves from a ramp-up to a mature period, as well as a stochastic component $v$, which reflects unexpected local and regional growth.

When $\omega$ is doubled from 0.20 to 0.40 , traffic growth sooner reaches a plateau and the option price rises to $\$ 199.62$ million, while if $\omega$ is halved, the option price falls dramatically to 
$\$ 633,090$. To see why such large changes in option price are plausible, consider first the case where traffic volume is expected to plateau very fast, perhaps after just three or four years. As volume and cash flow expectations are low, so is the ex-ante NPV of the CDA, and as a result the option's exercise price is also low. In that case, upside volatility has a large effect on the option price. If traffic volume is expected to grow steadily for the first 30 or 40 years of the lease, however, expected cash flows are substantial and upside volatility can have only a relatively small effect on further increasing revenues. Simply put, the exercise price is very high and it is unlikely the option will ever have a positive payoff, so its price must be low. Further note that in the case of Brownfield projects, traffic volume plateaus much sooner and is also less uncertain, so it should be expected that the option price would be, other things equal, much lower for a Brownfield than a Greenfield project.

The buyout option price is very sensitive to assumptions about traffic growth volatility $\mathrm{v}$. If $v$ is doubled from 0.01 to 0.02 , the option price increases substantially to $\$ 269.51$ million while if $v$ is halved, the option price falls to $\$ 97.74$ million. The reason is that if uncertainty about traffic growth rates is high, there is a good chance revenues will be substantially larger than expected. Unfortunately, $v$ is precisely the type of parameter that is difficult to estimate from historical data.

\subsubsection{Political/environmental risk and construction uncertainty}

While construction cost itself affects primarily the developer's level of senior debt, delays in construction imply that cash flows from the CDA have a lower NPV, so the buyout option will be worth less. Surprisingly, we find that this type of uncertainty does not appear to have a substantial effect on the option price. If we double from 0.15 to 0.30 the parameter $\sigma_{\mathrm{M}}$ 
that determines the variance of the project duration, the option price falls to $\$ 119.95$ million, while if he halve $\sigma_{\mathrm{M}}$, the option price increases to $\$ 123.34$ million.

\subsubsection{Discount rate uncertainty}

There is no consensus in the literature on what discount rate should be used for the public agency, but recent work suggests that the rate should be smaller for the government than for a private firm (Grout, 2003). In the baseline model, it was assumed that the government's discount rate is lower than the private sector's, but higher than the risk-free rate. Effectively the value was based on yields from low-risk municipal bonds. For purposes of sensitivity analysis, we consider the effect on the option price of letting the public agency's discount rate equal either the (lower) risk-free rate or the (higher) developer's discount rate.

If the public agency discounts at the same rate as the developer, as is frequently assumed in the empirical literature, then the option price falls to $\$ 23.75$ million. If however the public agency discounts at the risk-free rate, the option price increases to $\$ 356.76$ million. These results suggest that the appropriate choice of discount rate is critical to the accuracy of the solution and furthermore confirm the theoretical literature's findings that using the wrong discount rate can lead to an entirely different evaluation of the CDA and its clauses. This finding is not unlike the more general financial result whereby using an incorrect value for the financial beta, used to determine the risk premium, can lead to the wrong decision about a project's viability.

\section{Conclusion}

The need for innovative financing in public transportation budgeting has encouraged the use of transportation CDAs such as toll highway Build-Operate-Transfer arrangements and other leases and concessions. Although there are important benefits both for the private sector and for public authorities, there is also significant concern because of uncertainty regarding the long 
duration of such agreements, difficult to forecast revenue streams, and the potential for public backlash against toll increases.

This paper asks whether strategic options, included as clauses or special provisions in CDAs, can be of mutual benefit and therefore encourage the development of CDAs to address transportation financing difficulties. Although the framework is amenable to the analysis of a fairly wide range of problems, we focus on typical Greenfield highway CDAs, which appear to be one of the thorniest policy issues in this area.

A consumer demand-based framework is developed to analyze the sources of risk in CDAs, particularly in how they affect project cash flows, and examines the potential usefulness of strategic options to reduce uncertainty, focusing on the public sector. Model parameters are calibrated using estimates from historical data and results from the established literature. Monte Carlo simulation is used to price two strategic options in transportation CDAs, namely a buyout option and a revenue-sharing option. The first is modeled as a Bermudan call option, while the second is modeled as a sequence of European call options.

By definition, strategic or real options have non-negative value. However, it is difficult to know the price of such options without modeling them. Our findings suggest that both buyout and revenue-sharing options would be relatively expensive to include in a CDA, as they could be worth between one-quarter and one-third of the CDA concession price. The sensitivity analysis of key model parameters conducted in the paper shows that the option price solutions are robust to most, but not all, parameters. In particular, the accuracy of the option price solutions depends on the accuracy of the traffic volume and volume growth parameters, which are themselves estimated using available historical data on similar, existing CDAs. 
The objective of this paper was to investigate the potential usefulness of including strategic options, such as buyout clauses, in CDAs. To this end, we develop methods to accurately price strategic options in CDAs and tested the robustness of the solutions to potential model uncertainty. This paper finds that such options would have a high cost relative to the value of CDAs. As a result, it is understandable that private sector developers might be hesitant to allow options, given their large value relative to CDA concession prices, to be included in the agreement without compensation.

A simple but incomplete solution would be to make strategic options in CDAs more affordable by scaling down the option payoffs. For example, in the case of the revenue-sharing option, the fraction of excess revenues returned to the government could be reduced. Instead of the baseline 50 percent share, the government could receive a 20 or 30 percent share of excess revenues. Such an option should be much less expensive to include, yet would provide the public sector with a share of revenues in the event that the project's profitability is much higher than expected. Moreover, the government needs not include all of the annual revenue-sharing options, e.g., 50 options in the case of a 50-year CDA. It could include only a few, thereby reducing the cost substantially while maintaining a reasonable amount of revenue-sharing.

Likewise, the cost of the buyout option could be reduced by increasing the option exercise price, which is in the baseline model equal to the original CDA price. Thus, if buying back the CDA costs one and a half times the original concession value -50 percent more than the baseline-the public sector will only exercise the option if the project's profitability has increased dramatically. Because it is less likely to be used, the buyout option would have a lower price and would be less costly to include in a CDA. 
Therefore, the findings presented in this paper suggest that buyout and revenue-sharing options would be useful but very costly additions to CDAs. The paper also emphasizes that modified options with scaled-down payoff structures could be promising and more affordable alternatives to the baseline options. Finally, it is reasonable to conclude that, of the two options, revenue-sharing may be preferable because, while it reduces risk for the public sector, it does not increase uncertainty for the private sector as much as a buyout option might.

Further research could explore the potential usefulness of other types of strategic options not considered here, or could generalize the traffic volume model to incorporate for example High-Occupancy Vehicle (HOV) lanes and "shadow" toll pricing. 


\section{References}

Atkeson, A., and L.E. Ohanian. (2001). “Are Phillips Curves Useful for Forecasting Inflation?” FRB Minneapolis Quarterly Review (Winter) pp. 2-11.

Bain, R., and M. Wilkins (2002). "The Credit Implications of Traffic Risk in Start-Up Toll Facilities," August 2002, Standard \& Poor's, London.

Bain, R., and J.W. Plantagie (2007). "The Anatomy of Construction Risk: Lessons from a Millennium of PPP Experience,” April 2007, Standard \& Poor's, London.

Bel, G., and J. Foote (2007). "Comparison of Recent Toll Road Concession Transactions in the United States and France," working paper, Harvard University Kennedy School of Government.

Boyle, P. (1977). “Options: A Monte Carlo Approach,” Journal of Financial Economics 4: 32338.

Boyle, P., M. Broadie, and P. Glasserman (1997). "Monte Carlo Methods for Security Pricing," Journal of Economic Dynamics and Control, 21: 1276-321.

Broadie, M., and P. Glasserman (1997). "Pricing American-style Securities by Simulation," Journal of Economic Dynamics and Control 21: 1323-52.

Chan, K.C., G.A. Karolyi, F.A. Longstaff, and A.B. Sanders (1992). “An Empirical Comparison of Alternative Models of the Short-Term Interest Rate," Journal of Finance 47(3): 120927.

Cheah, C.Y.J., and J. Liu (2006). "Valuing Governmental Support in Infrastructure Projects as Real Options using Monte Carlo Simulation," Construction Management and Economics 24: $545-54$. 
Chiara, N. (2006). Real Option Methods for Improving Economic Risk Management in Infrastructure Project Finance. PhD dissertation, Columbia University.

Chiara, N., and M. Garvin (2008). "Variance Models for Project Financial Risk with Applications to Greenfield BOT Highway Projects," Construction Management and Economics 26: 925-39.

Chiara, N., M. Garvin, and J. Vecer (2007). "Valuing Simple Multiple-Exercise Real Options in Infrastructure Projects,” Journal of Infrastructure Systems 13(2): 97-104.

Cox, J.C., J.E. Ingersoll and S.A. Ross (1985). "A Theory of the Term Structure of Interest Rates," Econometrica 53: 385-407.

Crawley, J., and L. Lambert (2009). "Government Estimates \$20 Billion Highway Funding Shortfall.” Reuters, 25 June 2009.

Government Accountability Office (2008). Highway Public-Private Partnerships: More Rigorous Up-Front Analysis Could Better Secure Potential Benefits and Protect the Public Interest. Report to Congressional Requesters, February 2008. Washington, D.C.: Government Accountability Office.

Glasserman, P. (2003). Monte Carlo Methods in Financial Engineering. Berlin: Springer.

Grout, P. (2003). "Public and Private Sector Discount Rates in Public-Private Partnerships," Economic Journal 113: C62-C68.

Judd, K. (1998). Numerical Methods in Economics. Cambridge, MA: The MIT Press. Li, M.Z.F. (2008). "A Generic Characterization of Equilibrium Speed-Flow Curves,” Transportation Science 42: 220-35.

Longstaff, F., and E. Schwartz (2001). "Valuing American Options by Simulation: A Simple Least Squares Approach,” Review of Financial Studies 14: 113-47. 
Macquarie Infrastructure Group (undated). "Indiana Toll Road Presentation." Electronic file available at <http://www.macquarie.com.au/au/mig/acrobat/indiana_toll_road_presentation.pdf> Last accessed 7 December 2009.

National Cooperative Highway Research Program (2006). NCHRP Synthesis 364: Estimating Toll Road Demand and Revenue, A Synthesis of Highway Practice. Washington, D.C.: Transportation Research Board.

Peters, J., and A. Perotta (2006). "What Are the Best Practices?” Briefing Papers, Partnerships for New York: Innovative Transportation Financing and Contracting Strategies, Opportunities for New York State. Albany, NY: University Transportation Research Center.

Puentes, R., and R. Prince (2003). "Fueling Transportation Finance: A Primer on the Gas Tax," Brookings Institution Series on Transportation Reform, March 2003: 1-20.

Rose, S. (1998). "Valuation of Interacting Real Options in a Tollroad Infrastructure Project," Quarterly Review of Economics and Finance 38: 711-23.

U.S. Department of Transportation. (2012). "Refinements to DOT's Management of the Highway Trust Fund's Solvency Could Improve the Understanding and Accuracy of Shortfall Projections." Report Number: CR-2012-071.

Vasicek, O. (1977). “An Equilibrium Characterization of the Term Structure,” Journal of Financial Economics 5: 177-88. 
Table 1: Description of the model variables and parameters

\begin{tabular}{|c|c|c|}
\hline $\begin{array}{l}\text { Variable or } \\
\text { Parameter }\end{array}$ & Description & $\begin{array}{l}\text { Baseline } \\
\text { Value }\end{array}$ \\
\hline M & Duration of project construction, distributed truncated $N\left(\mu_{M}, \sigma_{M}^{2}\right)$ & $E[M]=3$ \\
\hline C & Annual cost of project construction, distributed truncated $N\left(\mu_{C}, \sigma_{C}^{2}\right)$ & $\mathrm{E}[\mathrm{C}]=\$ 200$ million \\
\hline$r_{e}$ & Developer's risk premium $r_{e}=r_{f}+\beta\left(r_{m}-r_{f}\right)$ & varies \\
\hline If & Risk-free rate approximated by the U.S. 3-month Treasury bill yield & varies \\
\hline $\mathrm{r}_{\mathrm{m}}$ & Market portfolio return & 0.10 \\
\hline$\beta$ & Financial beta for the company or industrial sector & 0.4 \\
\hline PHPTV & Peak-hour proportion of traffic volume, $0<x<1$ & 0.11 \\
\hline PTFTV & Proportion of trucks (for each axle class) as a fraction of total vehicles, $0<x<1$ & 0.5 (total) \\
\hline PTA & Proportion of toll avoidance, $0<x<1$ & 0.01 \\
\hline PHTV & Peak-hour traffic volume, in vehicles per hour per lane & 1800 \\
\hline AEPHTV & $\begin{array}{l}\text { Axle-equivalent peak-hour traffic volume, computed using the axle-equivalent of each } \\
\text { axle class of trucks }\end{array}$ & 2025 \\
\hline Lanes & Number of lanes in the CDA toll highway & 6 \\
\hline Days & Effective Days & 330 \\
\hline$A_{0}$ & $\begin{array}{l}\text { Baseline annual traffic volume when tolls are set to } 0 \text {, such that } A \text { equals } \\
{[(1-P T A) \times A E P H T V \div P H P T V] \times \text { NumberLanes } \times \text { EffectiveDays }}\end{array}$ & 36.085 million \\
\hline Q & $\begin{array}{l}\text { Quantity demanded, i.e., traffic volume for a given price (toll rate), such that } \\
Q=A(P+\psi)^{-\gamma}\end{array}$ & varies \\
\hline$P$ & Toll rate (if axle-equivalent) or vector of toll rates (if multiple vehicle classes) & varies \\
\hline$\psi$ & Parameter determining traffic volume upper bound as $P \rightarrow 0$ & 0.5 \\
\hline $\begin{array}{l}Y_{1} \\
Q_{0}\end{array}$ & $\begin{array}{l}\text { Elasticity of demand parameter } \\
\text { Maximum traffic volume ensuring average traffic speed does not fall below } V_{0}\end{array}$ & 0.3 (initial) \\
\hline $\mathrm{V}_{0}$ & $\begin{array}{l}\text { Average traffic speed below which the developer is financially penalized, based on the } \\
\text { correspondence } Q=Q_{0}\left(\frac{V}{V_{0}}\right)\left(1-\frac{1}{B} \ln \left(\frac{V_{f}-V}{V_{f}-V_{0}}\right)\right)^{-1}\end{array}$ & $80 \mathrm{~km} / \mathrm{h}$ \\
\hline$V_{f}$ & Free-flow average traffic speed & $110 \mathrm{~km} / \mathrm{h}$ \\
\hline B & Curvature parameter such that $B=V_{0} /\left(V_{f}-V_{0}\right)$ & 2.667 \\
\hline$g_{t}$ & Rate of traffic volume growth such that $g_{t}=g_{0} \exp \left(-\omega t+\sum_{\tau=1}^{t} v_{\tau}\right)$ & varies \\
\hline $\begin{array}{l}g_{0} \\
\omega\end{array}$ & $\begin{array}{l}\text { Initial period growth rate, distributed Uniform }(a, b) \text {, i.e., } a=0.15, b=0.50 \\
\text { Intensity of the deterministic downward trend in traffic growth }\end{array}$ & $\begin{array}{l}\mathrm{E}\left[g_{0}\right]=0.325 \\
0.20\end{array}$ \\
\hline $\mathrm{v}$ & Random shock to the growth rate, distributed truncated $N\left(0, \sigma_{v}^{2}\right)$ & $\mathrm{E}[\mathrm{v}]=0$ \\
\hline$A_{t}$ & Time-varying traffic volume base measure, $A_{t}=A_{0} \exp \left(g_{t}\right)$ & varies \\
\hline$x$ & $\begin{array}{l}\text { Effect on the elasticity parameter } \mathrm{y} \text { of improvements to competing roads, where } \mathrm{X} \text { is } \\
\text { distributed truncated } N\left(0, \sigma_{\chi}^{2}\right) \text { and may occur each period with a probability } \\
\text { distributed Bernoulli( } \mathrm{p})\end{array}$ & $E[X]=0$ \\
\hline T & Corporate tax on net revenues & 0.285 \\
\hline$\varsigma$ & Proportion of debt funded through equity, remainder through senior debt & 0.25 \\
\hline$\hat{\lambda}$ & $\begin{array}{l}\text { Parameter relating interest rate volatility to interest rate level in the CKLS interest rate } \\
\text { model }\end{array}$ & 1.5 \\
\hline a & Proportion of excess revenue-sharing returned to the public sector & 0.5 \\
\hline
\end{tabular}


Table 2: Option price solutions for the two options in CDAs considered in the project. Note that the stylized example of a CDA in the paper is modeled to have a value of \$456 million.

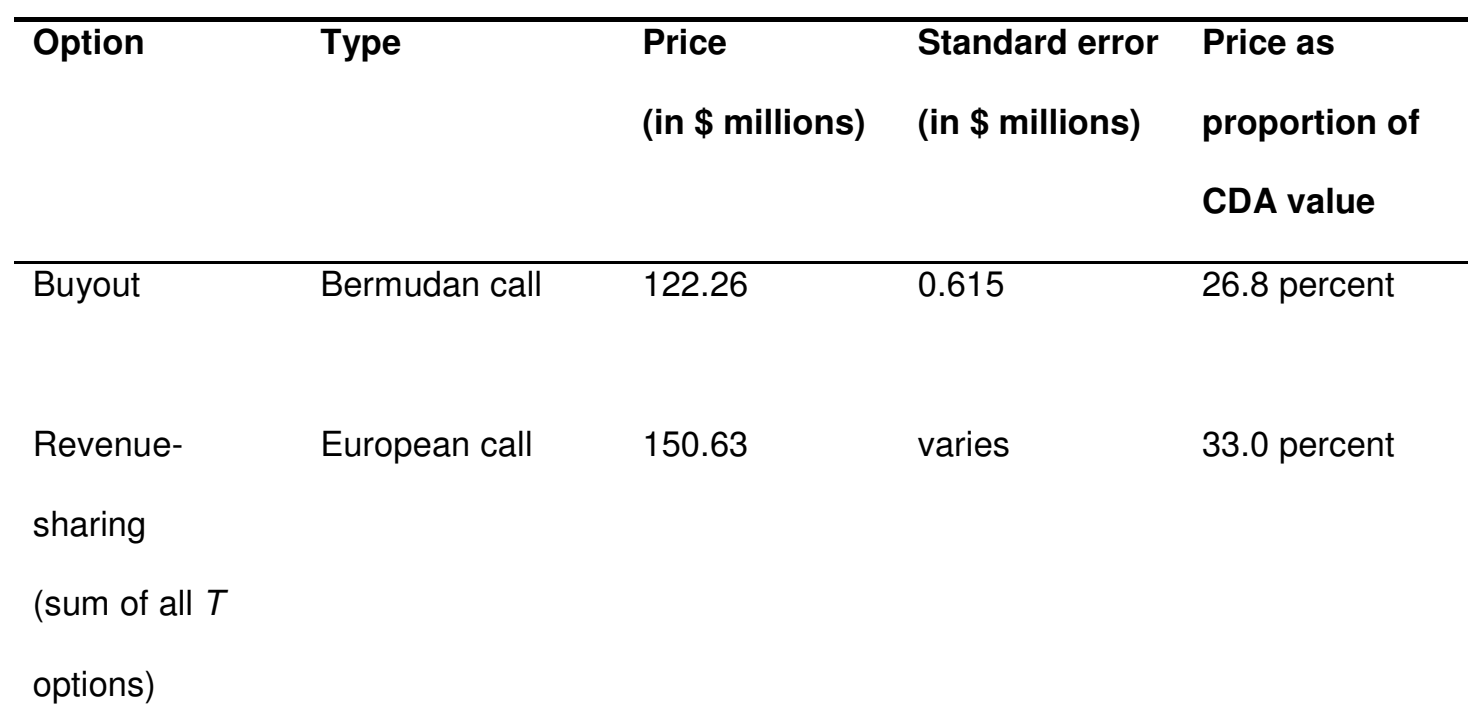

Note: Results are based on the author's calculations from 550,000 simulations generated from the model presented in the paper, discarding the first 50,000 as a burn-in stage. 
Table 3: Sensitivity analysis results for the buyout option price solution and selected model parameters, with a CDA concession period of $T=50$ years. The original buyout option price (for a $\$ 456$ million CDA) is listed alongside the revised option prices, when one parameter is changed and all else remains equal.

\begin{tabular}{|c|c|c|c|c|c|c|}
\hline \multirow[b]{2}{*}{ Parameter } & \multicolumn{3}{|c|}{$\underline{\text { Parameter }}$} & \multicolumn{3}{|c|}{ Option price ( $\$$ million) } \\
\hline & Low & Base & High & Low & Base & High \\
\hline Interest rate volatility $\sigma$ & 0.05 & 0.10 & 0.20 & 121.55 & 122.26 & 125.92 \\
\hline Interest rate long run level $b$ & 0.025 & 0.05 & 0.10 & 137.39 & 122.26 & 98.27 \\
\hline Inclusion of non-compete clause & & No & Yes & & 122.26 & 173.90 \\
\hline Standard deviation of log initial traffic volume $\sigma_{\mathrm{Q}}$ & 0.25 & 0.5 & 1.0 & 120.09 & 122.26 & 128.97 \\
\hline Peak hour traffic proportion & 0.042 & 0.07 & 0.14 & 79.93 & 122.26 & 155.61 \\
\hline Initial period vehicles per hour per lane & 600 & 1200 & 1800 & 84.74 & 122.26 & 140.69 \\
\hline Traffic growth deterministic trend $\omega$ & -0.10 & -0.20 & -0.40 & 0.633 & 122.26 & 199.62 \\
\hline Traffic growth volatility $v$ & 0.005 & 0.01 & 0.02 & 97.74 & 122.26 & 269.51 \\
\hline Volatility of $\log$ duration of construction $\sigma_{\mathrm{M}}$ & 0.075 & 0.15 & 0.30 & 119.95 & 122.26 & 123.34 \\
\hline Public sector discount rate $\delta$ & $\mathrm{r}_{\mathrm{f}}$ & $\mathrm{r}_{\mathrm{f}}<\delta<\mathrm{r}_{\mathrm{e}}$ & $\mathrm{r}_{\mathrm{e}}$ & 356.76 & 122.26 & 23.75 \\
\hline
\end{tabular}

Notes: Solution computed using 50,000 Monte Carlo runs (burn-in period of 5,000 runs). 


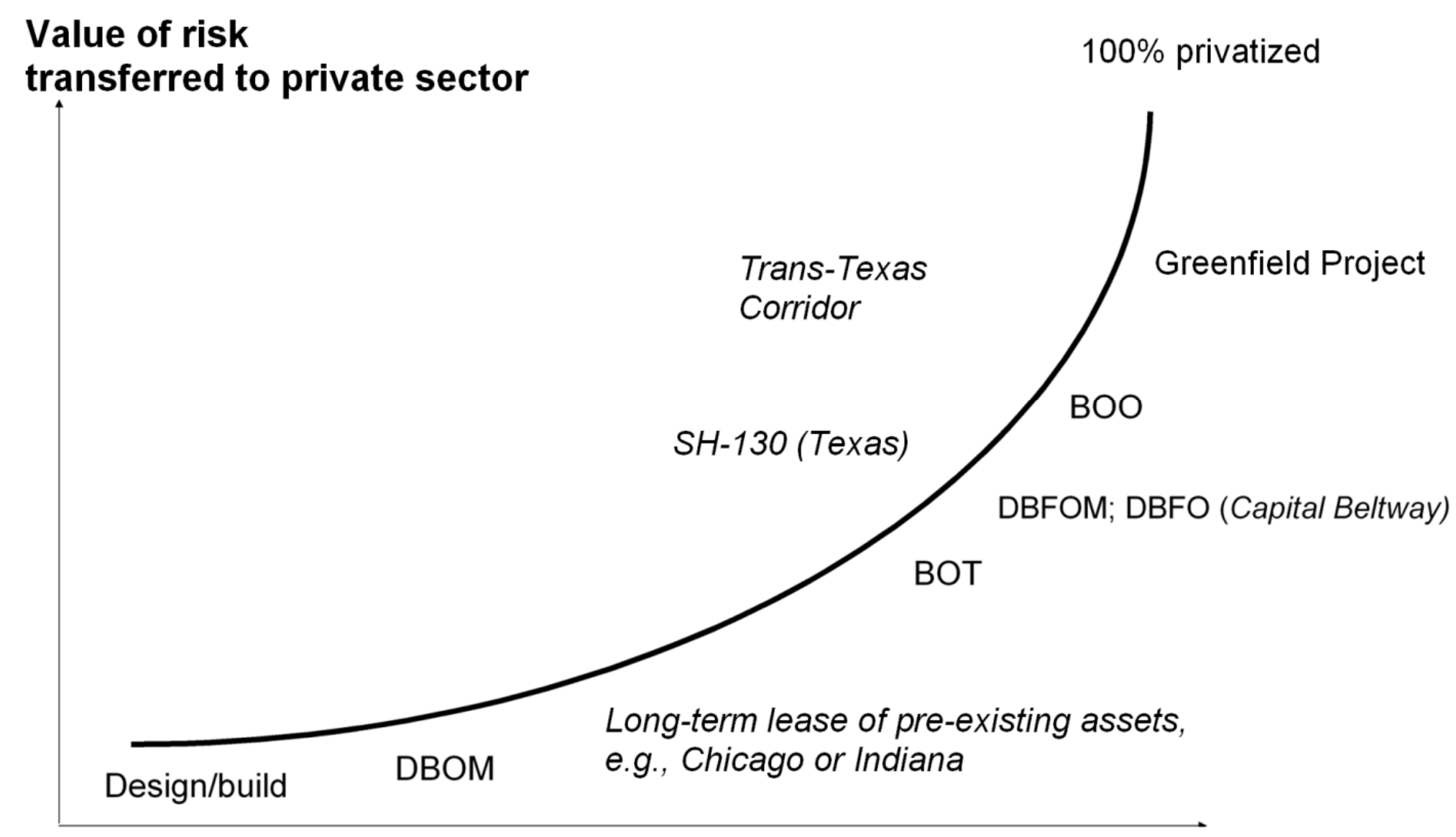

Increasing level of responsibility for the private sector

Figure 1. Illustration of how the value of risk transferred to the private sector is an increasing function of the degree of privatization of the project(i.e., delegation of responsibilities) 